\title{
Curing reaction mechanism of Bisphenol A (BPA) epoxy by way of non-isothermal DSC and phenomenological model
}

\author{
Zhao Juan $^{1, a *} \quad$ Liu Guang Ye $\mathrm{e}^{1, \mathrm{~b}}$ \\ ${ }^{1}$ Engineering Research Center of High Performance Polymer and Molding Technology of Ministry of \\ Education, Qingdao University of Science and Technology, Qingdao 266042, China \\ azhaojuanidc@126.com, bliugy@126.com
}

Keywords: Bisphenol A epoxy resin, phenomenological model, curing reaction kinetics, activation energy and reaction order, curing temperature

Abstract: Studied the curing reaction of bisphenol A epoxy resin DER331 system by the way of non-isothermal DSC and phenomenological model, using n-stage reaction and phenomenological model determined the curing kinetics equation, the results showed when the ratio of the epoxy resin DER331 and curing agent was 100:30, the activation energy Ea $=46950 \mathrm{~J} / \mathrm{mol}$, frequency factor $\mathrm{A}=2.08 \times 10^{6} / \mathrm{S}$, the reaction order of $\mathrm{n}=0.89$.

\section{Introduction}

Epoxy resins are a class of thermosetting polymer with good adhesion, corrosion resistance, electrical insulation, high strength and other properties. It has been widely used in a variety of metal and non-metal domain, such as corrosion-resistant coatings manufacturing, electrical insulating materials, fiberglass / composite materials, the electronic equipment, optical machinery, aerospace, marine transportation, high-speed trains, reducing vibration damping and biology, medicine, environmental protection materials and other different industrial fields [1] .

Epoxy curing is mainly based on thermal heating, radiation curing, and microwave curing process. Thermal curing resin matrix materials could cause uneven heating result to internal residual stress and deformation. The process of epoxy-based material are typical chemical reaction molding process, through the crosslinking reaction of the epoxy group and amido to form a three-dimensional network structure [2], therefore it is important to study the epoxy kinetics curing process to determine the optimal curing reaction conditions [3]. Differential scanning calorimetry (DSC) is the most effective method to study the behavior of epoxy curing, including isothermal and non-isothermal method [4]. In this paper, we selected DER331 bisphenol A epoxy resin, curing agent is a modified amine DEH622, the use of non-isothermal DSC method and phenomenological model to study the curing kinetics and curing process [5,6], with a view of the epoxy curing process to provide more valuable theoretical guidance.

\section{Experiments}

\section{Materials and equipment}

(1) Raw materials: Bisphenol A epoxy resin DER 331, colorless and viscous liquid, epoxy equivalent 182-192g/eq, viscosity 11000-14000 cps @ 25 C, Shanghai Xinzhengxing International Trade Co., Ltd. of Dow Chemical;

Hardener DEH622, low-temperature fast amine curing agent, Shanghai Xinzhengxing International Trade Co., Ltd. of Dow Chemical; ratio of epoxy resins and curing agents for 100:30

(2) The laboratory instruments and testing condition

Differential Scanning Calorimetry: DSC-1, Switzerland Mettler-Toledo International Inc., nitrogen atmosphere;

Curing kinetics test conditions: $-50 \sim 300^{\circ} \mathrm{C}$, the heating rate were $2.5 \mathrm{~K} / \mathrm{min}, 5 \mathrm{~K} / \mathrm{min}, 10 \mathrm{~K} / \mathrm{min}$, $15 \mathrm{~K} / \mathrm{min}, 20 \mathrm{~K} / \mathrm{min}$. 


\section{Results and discussion}

\section{The basic law of epoxy resin curing kinetics}

Generally we use the Kissinger equation [7] and Crane equation [8] for the different heating rates DSC data were processed to obtain $\mathrm{Ea}, \mathrm{A}$ and $\mathrm{n}$ and other kinetic parameters.

Kissinger equation:

$$
\ln \frac{\beta}{\mathrm{T}_{\mathrm{P}}^{2}}=\left(\ln \frac{\mathrm{A} \times \mathrm{R}}{\mathrm{E}_{\mathrm{a}}}\right)-\frac{\mathrm{E}_{\mathrm{i}}}{\mathrm{RT}}
$$

Crane equation:

$$
\frac{\mathrm{d}[\ln \beta]}{\mathrm{d}\left(1 / \mathrm{T}_{\mathrm{P}}\right)}=-\left(\frac{\mathrm{E}_{\mathrm{a}}}{\mathrm{nR}}+2 \mathrm{~T}\right.
$$

Where $\beta$ - heating rate, $\mathrm{K} / \mathrm{min}$;

Tp - DSC curve peak temperature, $\mathrm{K}$;

$\mathrm{R}$ - ideal gas constant, $8.314 \mathrm{~J} /(\mathrm{mol} \bullet \mathrm{K})$;

$\mathrm{Ea}$ - activation energy. $\mathrm{J} / \mathrm{mol}$

Where: $\beta$ is the heating rate, and Tp is the peak temperature of the DSC curve. When $\mathrm{Ea} / \mathrm{nR}$ is much larger than $2 \mathrm{Tp}$, Crane equation $2 \mathrm{Tp}$ can be ignored.

\section{DSC curves of different heating rates}

Process parameters of the curing system can not be determined directly by way of single isothermal DSC scanning method, in this experiment we take different heating rate of $2.5,5,10,15$, and $20 \mathrm{~K} / \mathrm{Min}$, the optimum ratio of DER 331 and curing agent DEH622 were 100:30, the temperature ranges from $-50{ }^{\circ} \mathrm{C}$ to $300{ }^{\circ} \mathrm{C}$, DSC curve is shown in Fig.1.

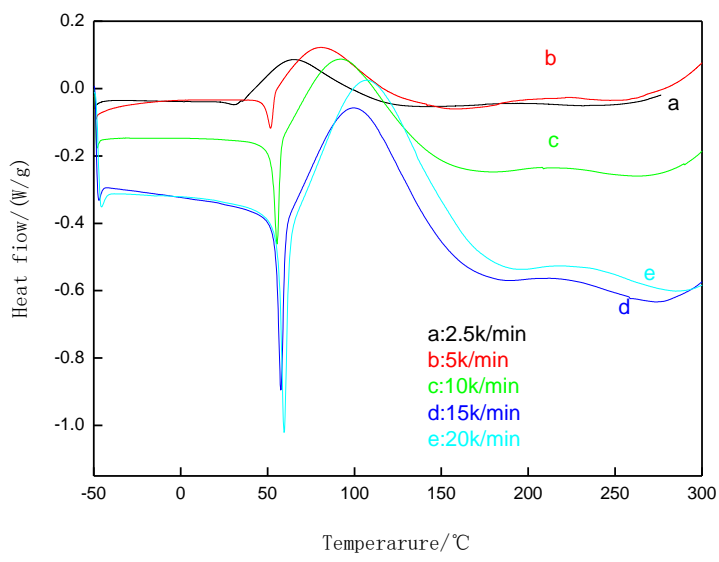

Fig. 1 Different heating rates of DSC curing curves

We derived data from different DSC curve at different heating rates, the heat flow, the initiation temperature and the curing top temperature as shown in Table 1. DSC curves (Fig. 1) and data (Tabel 1) showed the exothermic regular pattern of curing reaction, we could explain the phenomena as the following: with the increase of the heating rate, $\mathrm{dH} / \mathrm{dt}$ increases, due to the thermal hysteresis, the heat transporting and the temperature cannot be instantaneous, the heat flow lagged behind the temperature, therefore the heat flow, initiation curing temperature, the peak temperature in the process of curing shift to the higher temperature direction. 


\begin{tabular}{cccccc}
\hline Heat rate $(\mathrm{K} / \mathrm{min})$ & 2.5 & 5 & 10 & 15 & 20 \\
\hline Heat flow $(\mathrm{w}, \mathrm{J} / \mathrm{g})$ & 149.35 & 94.27 & 80.98 & 87.63 & 84.62 \\
$\mathrm{~T}_{0}\left({ }^{\circ} \mathrm{C}\right)$ & 34.82 & 53.71 & 58.82 & 61.68 & 64.96 \\
$\mathrm{~T}_{\mathrm{p}}\left({ }^{\circ} \mathrm{C}\right)$ & 65.10 & 81.11 & 93.52 & 101.23 & 108.01 \\
\hline
\end{tabular}

Table 1 Different heating rate, heat flow, initiation curing temperature, and the peak temperature

\section{Determine curing reaction activation energy and frequency factor}

The apparent activation energy of the curing system could be obtained by way of the non-isothermal DSC data and Kissinger equation (Eq. 1) or Crane equation (Eq. 2) to obtain $\ln \left(\beta / T_{P}^{2}\right)$ and $1 / T_{P}$ linear relationship, which could calculate the Ea and the apparent frequency factor $\mathrm{A}$. The data were shown in Table 2, do plot of $\ln \left(\beta / T_{P}^{2}\right)$ and $1 / T_{P}$ fitting line to get a straight line as Fig. 2.

Put the intercept 5.90835 and slope -5647.62 into Kissinger equation (Eq. 1) got the result:

$$
\begin{aligned}
& \ln \frac{A \times R}{E_{a}}=5.90835 . \\
& -\frac{E_{a}}{R}=-5647.62 .
\end{aligned}
$$

We got: $\mathrm{Ea}=46954 \mathrm{~J} / \mathrm{mol}=46.954 \mathrm{~kJ} / \mathrm{mol}, \mathrm{A}=2.08 \times 10^{6} \mathrm{~s}^{-1}$

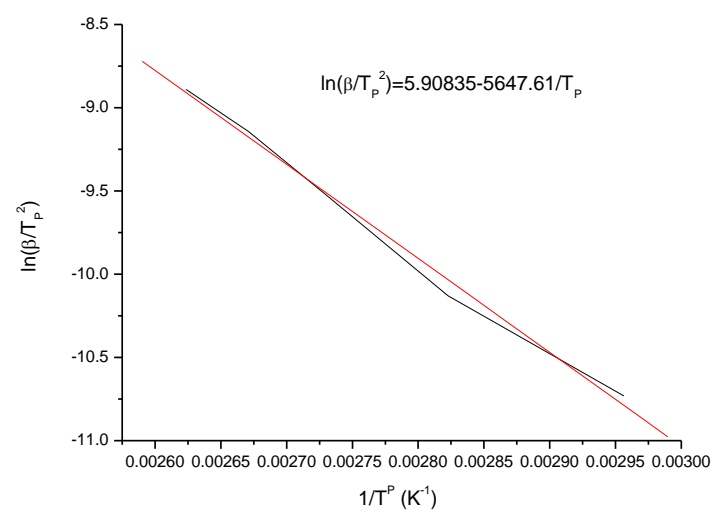

Fig. 2 Relationship between $\ln \left({ }^{\beta} / T_{P}^{2}\right)$ and ${ }^{1} / T_{P}$

\section{Determine reaction order}

According to Crane equation, when $\mathrm{Ea} / \mathrm{nR}$ is much larger than $2 \mathrm{Tp}, 2 \mathrm{Tp}$ in the equation can be ignored, in this case, we got a curve and fit line. Do $\ln \left(\beta / T_{P}^{2}\right)$ and $1 / T_{P}$ plot to get a linear straight line as showed in Fig. 3. According to the slope, we could use the equation (Eq. 2) to calculate the reaction order $n$.

$$
-\left(\frac{E_{a}}{n R}\right)=-6364.61 \text {. }
$$

$\mathrm{Ea}=46954 \mathrm{~J} / \mathrm{mol} ; \mathrm{A}=2.08 \times 10^{6} \mathrm{~s}^{-1} ; \mathrm{n}=0.89$. 


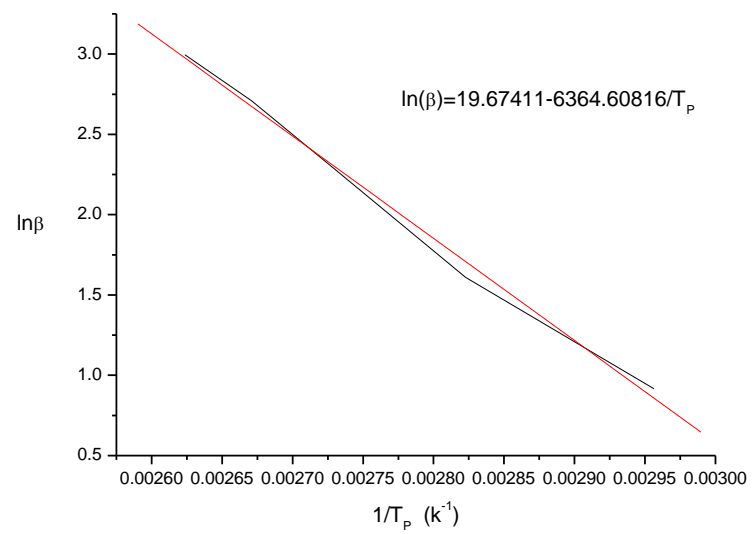

Fig 3 Relationship between $\ln \beta$ and ${ }^{1} / T_{P}$

\section{Conclusion}

Using the non-isothermal DSC method, n-order reaction model and Malek theory study the curing kinetics of the bisphenol A epoxy resin system, we could determine that the activation energy $\mathrm{Ea}$ is $46950 \mathrm{~J} / \mathrm{mol}$, the frequency factor $\mathrm{A}$ is $2.08 \times 10^{6} / \mathrm{S}$, the reaction order is 0.89 , therefore mathematical model could guide and control the epoxy resin curing process.

\section{Literature References}

[1] Chen Ping, Liu Sheng Ping, Epoxy resin and its application [M] Beijing: Chemical Industry Press, 2011.

[2] Zhu Ai Shi, Zheng Chuan Xiang etc. Review of Matrix Solidification and Forming Processes of Composite Materials [J],Journal of Zhejiang University of Science and Technology, 2008,20(4):269-273.

[3] Zhang Ming, An Xue Feng, Tang Bang Ming, YI Xiao Su. Cure kinetics and TTT diagram of a bicomponent high performance epoxy resin for advanced composites [J]. Acta Materiae Compositae Sinica, 2006,(01):17-25.

[4] Li Heng, Wang Dehai, etc., Research of Epoxy Resin Curing Kinetics and Application [J]. Fiber Reinforced Plastics/Composites, 2013(4):43-50

[5] Málek J. The kinetic analysis of non-isothermal data[J]. Thermochimica acta, 1992, 200: 257-269. [6]Vyazovkin S. Thermal analysis [J]. Anal Chem,2008,80 (12):4301)

[7] Kissinger H E. Reaction kinetics in differential thermal analysis[J]. Analytical chemistry, 1957, 29(11): 1702-1706.

[8] Crane L W, Dynes P J, Kaelble D H. Analysis of curing kinetics in polymer composites[J]. Journal of Polymer Science: Polymer Letters Edition, 1973, 11(8): 533-540. 